\title{
Digital devices, internet-enabled toys and digital games: The changing nature of young children's learning ecologies, experiences and pedagogies
}

Lorna Arnott, Strathclyde University

loanna Palaiologou, UCL

Colette Gray, Stranmillis Univeristy College.

\section{Editorial}

Digital technologies as part of young children's lives - from birth to eight years old have been a source of debate in the media and in academic fields for more than a decade. This discussion has increased in popularity since the introduction of the first iPad in 2010, after which digital devices became increasingly accessible for young children's fine motor capabilities. Subsequently, the evolution of digital devices for young children has progressed at a rapid rate. Already, in less than 10 years, touchscreen devices are beginning to be displaced by a shifting focus on newly available internet-connected toys (loToys), which mimic the Internet of Things in the toy market (Mascheroni and Holloway, 2017).

With increasingly accessible devices in terms of cost, user friendly interfaces and tactile technologies - the concreteness of which link to the founding principle of early childhood pedagogy - research shows that young children are engaging widely with these devices. For example, from birth children have been found to observe screenbased communication such as video calls with distant grandparents (McClure et al., 2018), and before their first birthday can begin to autonomously manoeuvre the user interface by swiping (O'Connor, 2017). Toddlers are known to access photographs and videos; navigate Youtube, and interact with and complete some age appropriate digital games and applications (Harrison, 2018). This research demonstrates the competence of very young children as users of digital media.

Consequently, a growing body of research now focuses on how young children engage in the digital contexts in which they live and the impact this can have on all aspects of their lives (Palaiologou, 2016). The discussions investigate the impact that digital devices have on social interactions (Eagle, 2012), cognitive development and specific forms of learning, such as literacy and numeracy (Sinclair, 2018; Voogt and McKenney, 2017) as well as their daily routines and lifestyles (Plowman and 
McPake, 2013). Similarly, the prevalence of technologies in children's lives and learning have led to (re)conceptualisations of childhood by theorising children's play with digital technology. These attempts come mainly from cultural-historical perspectives (Fleer 2016) or draw attention "to the ways in which [...] "ecology" and "context", are often used by default when discussing the cultures of children's [digital] everyday lives" (Plowman, 2016, p. 190). They seek to move away from the tendency to position technologies as agentic artefacts that significantly impact, either positively or negatively, on the child's development and learning, with children being powerless to stop it.

This special issue, echoes a key conclusion from existing research that we should move beyond debates about inclusion of media in children's lives towards conceptualising the quality of technological experiences in our early childhood digital landscapes (Fleer 2016, Marsh 2017). Thus, a nuanced stance is sought here, whereby the role of technologies is positioned within broader ecological discussions of children's digital worlds. It seeks to examine diverse theoretical positioning and epistemological standpoints in early childhood pedagogy with technologies. In that sense, the collection of twelve papers presented here, aims to make us rethink our understanding of the contextual, social, cultural and pedagogical factors which together frame children's experiences with digital technologies. Moreover, it attempts to provide a platform for early childhood education on how technologies can be an effective part of a pedagogy that bridges digital and non-digital resources to create playful learning narratives for young children (Stephen and Plowman 2014, Arnott 2016a, Edwards et al 2017).

The papers included here go beyond the transitional nature of research focusing on children's explorations using digital devices. No longer is it sufficient merely to explore the bounded experience of the child with digital technologies, or to investigate only the human-computer interaction as a separate or disjointed activity from traditional early childhood pedagogical experiences. Digital technologies are increasingly evident in children's play worlds and research is reflecting this evolutionary role with conceptualisation that adds to ontological discussions on children's play in the twenty first century. 
This issue is divided into discussions of Home Life; Pedagogies and Curriculum; and Play.

We start with the issue of Home Life in order to situate the later papers in an understanding of the child's everyday world. Brito et al. in their paper Young children, digital media, and smart toys: How perceptions shape adoption and domestication, provide a contextualised understanding of the ways in which children's technological toys are becoming domesticated in everyday lives in Portugal. It offers an understanding of the consumerisation of children's worlds described through the way children recognised and sought out technologies from advertising. Adding to this narrative, Huber et al. offer an in-depth understanding of how children engage with digital technologies in the Australian context, through their paper Detailing the digital experience: Parent reports of children's media use in the home learning environment. In doing so, it moves our understanding beyond the focus on screen-time towards the quality of experience.

An holistic understanding of children's digital lives outside of school then feeds into the Pedagogies and Curriculum discussions of children's digital experience. Practitioners and teachers first need to understand the whole child before we can plan for possibilities with technologies or indeed speak of the child centred approach to learning (Woods, 2017). Understanding the mesosystemic link between home and school microsystems (Bronfenbrenner, 2009) is offered by Gillen and

Kucirkova in their post-humanist approach to documenting the child's digital journey across home and school in the UK. Their paper Percolating spaces: Creative ways of using digital technologies to connect young children's school and home lives, provides enhanced vignettes of the way the child connects with digital technologies across these two contexts and offers detailed narrative accounts of the children's, teachers' and parents' engagement with these learning spaces. Yelland seeks to describe this complexity and multidimensional nature of the child's digital world in her paper A pedagogy of multiliteracies: Young children and multimodal learning with tablets. While set in the Australian context, the internationally relevant debate challenges the reliance of research on digital lives by suggesting that "the main difference about learning in the 21st century is not that it is digital, but rather that it is multimodal". These examples of multi-literacies and multi-modalities are again translated into practical application in the next two papers. In both Northern Ireland 
and Republic of Ireland contexts, through Dunn and Sweeney paper, Writing and iPads in the Early Years: Perspectives from within the classroom, children express their view that iPads provide more choice and creativity in their compositional writing skills. While in the UK, creative play is shown through the empirical work of Marsh et al. in their paper Play and creativity in young children's use of apps.

This recognition of changing childhoods into a multimodal realm leads to pressure on changing practices. This poses questions about the role of digital technologies in the educational lives of very young children and the competence of practitioners and teachers to support such integration. While we know digital devices are used by children under 3 years old in the home, the role of such technologies in aligning with high quality early childhood pedagogies is still fraught with anxiety. Hatzigianni and Kalaitzidis, in their paper Early childhood educators' attitudes and beliefs around the use of touchscreen technologies by children under three years of age, demonstrate the paradox between practitioners' confidence with digital devices in their own lives, compared to implementing them as pedagogical tools for very young children in the Australian context. This ability to integrate technologies is also firmly rooted in practitioner beliefs and confidence in later childhood, which stems from instilling a sense of empowerment, as Johnston et al. articulate in their paper Supporting young children as digital citizens: The importance of shared understandings of technology to support integration in play-based learning. They demonstrate that in the Australian context confidence in practice with digital technologies is complex and socio-culturally framed.

When changing practices and approaches to Play with digital technologies are widely embraced there are additional opportunities for learning and development, both for the children and practitioners. For example Crompton et al. in their paper Humanoid robots supporting children's learning in an early childhood setting present one of the first papers to document the role of humanoid robots in early childhood education. They explore practice in the Southeastern states of the United States of America and detail the significant role humanoid robots can have in the social and emotional development of children. Such an innovative approach to practice however, requires training and support for practitioners to frame the experience skilfully. Indeed, as has been articulated elsewhere, digital technologies do not take 
on the role of pedagogical planning for us which must be adequately undertaken in light of the ecological context (Arnott, 2016).

With practitioner confidence and training comes an ability to integrate digital devices in to a play-based pedagogy, which is fundamental to learning in early childhood. For example, Hatzigianni et al. in Using tablets in free play. The implementation of the digital play framework in Greece demonstrate how Bird and Edwards (2015) Digital Play Framework can transcend contexts and cultures and successfully be applied in Greece. Knowledge of the ecological framing of children's technological play in the ways described throughout this issue, lead to innovative practices and pedagogies. It is this holistic view of the role digital technologies can play in learning which leads to engaging approaches in early childhood education. For example in the paper by Fleer Digital animation: New conditions for children's development in play-based setting we see how innovative approaches, such as animation in early childhood, provides now possibilities for digital technologies to extend children's learning. Similarly, approaches which challenge the moral panics associated with the use of digital devices in contemporary childhood (e.g. Palmer, 2015) and embrace their possibilities, can be seen through the work of Danby et al. in their paper Situated collaboration and problem solving in young children's digital game play. With data from Australia, Norway and Sweden, we see evidence of gaming, challenging the notion of it being a solitary activity and demonstrating its potential for peer learning and social interaction.

As editors for this special issue it has been our pleasure to read about innovative research which is driving practice in early childhood education and adds to ontological and epistemological discussions on play based pedagogy. The interest in the call for papers was phenomenal and is a testament to the significance of digital technologies in early childhood education. We are delighted, therefore, to be able to showcase such diverse internationally based research projects on the topic of childhood in the current era. Across the issue, the body of work does not position digital technologies as an omnipotent tool which is capable to transforming children's lives and learning, rather it seeks to present a contextualised exploration of childhoods across the world. It is this holistic understanding which will drive practice forward. Thus, the collection of papers presented here demonstrate that through understanding ecologies and experiences in a digital era we are changing theoretical 
underpinnings of the nature of early childhood digital pedagogy in the twenty first century.

\section{References}

Arnott L. (2016) The Role of Digital Technologies. In: Palaiologou I (ed) The Early Years Foundation Stage: Theory and Practice. London: SAGE.

Bird J and Edwards S. (2015) Children learning to use technologies through play: A Digital Play Framework. British Journal of Educational Technology 46: 1149.

Bronfenbrenner U. (2009) The ecology of human development: Harvard university press.

Eagle S. (2012) Learning in the early years: Social interactions around picturebooks, puzzles and digital technologies. Computers \& Education 59: 38-49.

Fleer, M. (2016). Theorising digital play: A cultural-historical conceptualisation of children's engagement in imaginary digital situations. International Research in Early Childhood Education, 7 (2), pp, 75-90.

Harrison E and McTavish M. (2018) 'i'Babies: Infants' and toddlers' emergent language and literacy in a digital culture of iDevices. Journal of Early Childhood Literacy 18: 163-188.

Marsh, J.A., (2017). The Internet of Toys: a posthuman and multimodal analyse 0 connected play. Teachers College Record, 119, 120305, ISSN 0161-4681, pp.1-32.

Mascheroni G and Holloway D. (2017) The Internet of Toys: A report on media and social discourses around young children and loToys. DigiLitEY.

McClure ER, Chentsova-Dutton YE, Holochwost SJ, et al. (2018) Look At That! Video Chat and Joint Visual Attention Development Among Babies and Toddlers. Child Development 89: 27-36.

O'Connor J. (2017) Under 3s and Technology. In: Arnott L (ed) Digital Technologies and Learning in the Early Years. London: SAGE, 87-98.

Palmer S. (2015) Toxic Childhood: How The Modern World Is Damaging Our Children And What We Can Do About It: Orion.

Plowman, L. (2016). Rethinking context: Digital technologies and children's everyday lives. Children's Geographies, 14:2, 190-202.

Plowman L and McPake J. (2013) Seven Myths About Young Children and Technology. Childhood Education 89: 27-33. 
Sinclair N. (2018) Time, immersion and articulation: Digital technology for early childhood mathematics. Contemporary research and perspectives on early childhood mathematics education. Springer, 205-221.

Stephen, C., and Edwards, S. (2018). Young children Playing and Learning in a Digital Age: A cultural and Critical Perspective. London: Routledge.

Stephen, C. and Plowman, L. (2014). Digital play. In L. Brooker, M. Blaise and S. Edwards (Eds.), Sage handbook of play and learning in early childhood (pp. 330341). London: Sage.

Voogt $\mathrm{J}$ and McKenney S. (2017) TPACK in teacher education: Are we preparing teachers to use technology for early literacy? Technology, pedagogy and education 26: 69-83.

Woods A. (2017) Child-initiated Play and Learning: Planning for Possibilities in the Early Years, Oxon: A David Fulton Book, Routledge. 